Energy Research Journal 1 (2): 116-119, 2010

ISSN 1949-0151

(C) 2010 Science Publications

\title{
A Study of Solar Reflector Efficiency of Parabolic Dual Trough
}

\author{
Sopa Cansee, Adisak Pattiya, Singthong Pattanasethanon and Worraphan Sombuttera \\ Department of Mechanical Engineering, Faculty of Engineering, Mahasarakham University, \\ Kamriang, Kantharawichai, Mahasarakham 44150, Thailand
}

\begin{abstract}
Problem statement: The receiver of parabolic dual trough had been designed and built in order to increase efficiency of solar radiation accumulation by using iron-aluminum sheet as an intermediate in receiving heat and it is the study into how to benefit from solar radiation energy. This research proposed the principle of changing solar radiation to be heating energy by using aluminum sheet made into dual parabolic curve tilted with iron-aluminum sheet which was receiver of radiation reflection. Approach: This dual parabolic curve could be adjusted so that heat obtained from the solar radiation accumulation, which was the focus, could spread around iron-aluminum sheet. In testing of heating by solar energy, the unit would be tilted at $16^{\circ}$ to the North-South in order to receive solar radiation and the unit was arranged horizontally. The test was classified into 4 conditions including (1) laying the unit horizontally and un-drive the motor, iron-aluminum sheet would be put in place unmoved in vertical line; (2) laying the unit horizontally and drive motor so that iron-aluminum sheet could be moved upwards and downwards along the vertical line; (3) laying the unit to be tilted at $16^{\circ}$ with plane level and un-drive motor and (4) laying the unit to be tilted at $16^{\circ}$ with the plane level and drive motor so that iron-aluminum sheet could be moved upwards and downwards along the vertical line. Results: It was found from the test of temperature of iron-aluminum sheet that on the first condition, the highest temperature of iron sheet was $75.2^{\circ} \mathrm{C}$ and the highest temperature of aluminum was $84.7^{\circ} \mathrm{C}$; on the second condition, the highest temperature of iron sheet was $90.6^{\circ} \mathrm{C}$ and the highest temperature of aluminum was $97.2^{\circ} \mathrm{C}$; on the third condition, the highest temperature of iron sheet was $87.4^{\circ} \mathrm{C}$ and the highest temperature of aluminum was $93.4^{\circ} \mathrm{C}$; on the fourth condition, the highest temperature of iron sheet was $94.5^{\circ} \mathrm{C}$ and the highest temperature of aluminum was $89.4^{\circ} \mathrm{C}$. Therefore, the test of laying the unit to be tilted at $16^{\circ}$ with the plane level and driving motor leaded to the high temperature since the perpendicular of light and the spreading of sunlight from dual parabolic curve could cover all area. Conclusion: These results indicate dual parabolic curve could be increased efficiency of solar radiation accumulation by using iron-aluminum sheet as an intermediate in receiving heat.
\end{abstract}

Key words: Solar radiation, dual parabolic trough, iron-aluminum sheet

\section{INTRODUCTION}

The sun is an object that is vital to human life. It is the center of our solar system; it is the powerful source of energy. Energy is essential to daily life of all life. Men, through various ages, have been developing the use of energy; energy from firewood, wind energy, hydro energy, coal, petroleum, natural gas, as well as nuclear energy. The use of energy tends to increase rapidly. It is expected that there will be no more petroleum left on earth within around 50 years and there will be no more coal left on earth in around 100 years (Energy Research Institute, 2009). Furthermore, the use of energy causes pollution to environment including acid rain, green house effect, increased dust and increased toxic gas in the air (Craxford, 1983; Gao and Chen, 2008).

Solar energy is renewable energy; consequently, there is unlimited amount of it to be used. The users can directly use it comprehensively. It is the source of clean energy and does not pollute environment. Normally, men already use solar energy in daily life. The solar radiation intensity in Thailand is about $18 \mathrm{MJ} \mathrm{m}^{-2}$ day almost all year (Ministry of Energy, 2008); therefore, the potential to use solar energy is very high.

Corresponding Author: Sopa Cansee, Department of Mechanical Engineering, Faculty of Engineering, Mahasarakham University, Kamriang, Kantharawichai, Mahasarakham 44150, Thailand Tel: +66-43754321 Fax: +66-43754316 
Therefore, in this research, receiver of parabolic dual trough had been designed and built in order to increase efficiency of solar radiation accumulation by using iron-aluminum sheet as an intermediate in receiving heat and it is the study into how to benefit from solar radiation energy.

\section{MATERIALS AND METHODS}

The tool used in receiving solar energy consists of structure of receiver of solar energy, parabolic dual trough which could be adjusted and was made of aluminum sheet with reflection coefficient of about 0.8 and was easily burnished without rust and with high flexibility; so, it could be easily assembled, receiver of reflection radiation (iron and aluminum sheet with the size of $38.5 \times 29.5 \mathrm{~cm}$ ) from parabolic dual trough and the kit controlling the moving of radiation reflection receiver (Fig. 1). The sunlight provides heating energy to dual parabolic curve and leads to light accumulation at the focus then reflects to the existing unit in vertical line and could move upwards and downwards.

In the experiment of heating receiver of dual parabolic curve, the period of $9.00 \mathrm{am} .-3.00 \mathrm{pm}$. when the sunlight was of the highest level of intensity was selected. The sunlight intensity was recorded with Pyranometer, EKO brand, MS-64 model, accuracy of $\pm 50 \mathrm{mV}$ testing period. Lay the unit horizontally and tilted at 16 Degree with the plane level. Record temperature every 15 minutes by type-K thermocouple and data logger with Yokogawa brand and MX100 model at the iron and aluminum sheet, internal temperature of solar receiver and ambient temperature.

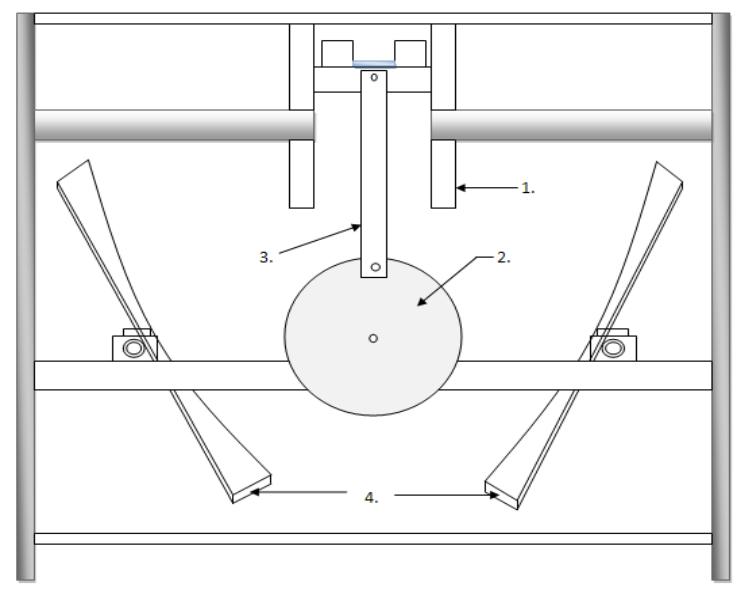

Fig. 1: Experimental equipment set up (1) ironaluminum sheet; (2) reflection receiver; (3) unit moving vertical line; (4) parabolic trough
The measurement of such temperature was classified into 4 conditions including (1) laying the unit horizontally and un-drive the motor, iron-aluminum sheet would be put in place unmoved in vertical line; (2) laying the unit horizontally and drive motor so that iron-aluminum sheet could be moved upwards and downwards along the vertical line; (3) laying the unit to be tilted at $16^{\circ}$ with plane level and un-drive motor and (4) laying the unit to be tilted at $16^{\circ}$ with the plane level and drive motor so that iron-aluminum sheet could be moved upwards and downwards along the vertical line.

Take temperature value plotted in graph and time to calculate heating value of iron and aluminum sheet from Equation:

$$
\mathrm{Q}=\mathrm{mC}_{\mathrm{p}}\left(\mathrm{T}_{2}-\mathrm{T}_{1}\right)
$$

Where:

$\mathrm{Q}=$ Heating value $(\mathrm{kJ})$

$\mathrm{m}=$ Mass of materials $(\mathrm{kg})$

$\mathrm{C}_{\mathrm{p}}=$ Specific heat capacity $\left(\mathrm{kJ} \mathrm{kg}^{-1}{ }^{\circ} \mathrm{C}\right)$

$\mathrm{T}_{2}=$ Temperature of material $\left({ }^{\circ} \mathrm{C}\right)$

$\mathrm{T}_{1}=$ Temperature of environment $\left({ }^{\circ} \mathrm{C}\right)$

\section{RESULTS}

Temperature of the unit moving upwards and downwards in vertical line and laying test kit horizontally: Fig. 2 shows solar energy intensity on the condition of laying the testing tool horizontally and the unit moving upwards and downwards in vertical line; the sunlight intensity tends to increase from $9.00 \mathrm{am}$. and with the highest level of intensity of $974 \mathrm{~W} \mathrm{~m}^{-2}$ at $12.15 \mathrm{pm}$. And after that, it tends to decrease that looks like an inverted parabola. From such graph, it shows that the sunlight intensity is high during $12.00-1.00 \mathrm{pm}$ when the light is perpendicular with testing area. Temperature of testing kit on such condition is shown in Fig. 3.

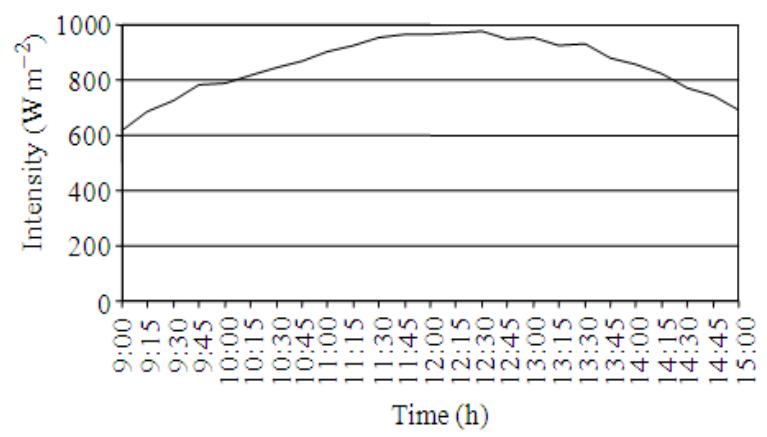

Fig. 2: Solar energy intensity 
Energy Rec. J. 1 (2): 116-119, 2010

Table 1: Result of temperature and heating value of iron sheet

\begin{tabular}{|c|c|c|c|c|c|}
\hline \multicolumn{2}{|c|}{ Testing condition } & \multicolumn{4}{|c|}{ Temperature $\left({ }^{\circ} \mathrm{C}\right)$} \\
\hline & & Min & $\operatorname{Max}$ & Heating value $(\mathrm{kJ})$ & Ambient temperature $\left({ }^{\circ} \mathrm{C}\right)$ \\
\hline Horizontal & Un-drive motor & 55.3 & 75.2 & 24.90 & 33.39 \\
\hline Horizontal & Un-drive motor & 75.5 & 90.6 & 19.58 & 36.94 \\
\hline $16^{\mathrm{o}}$ & Un-drive motor & 57.2 & 87.4 & 8.70 & 34.04 \\
\hline $16^{\circ}$ & Drive motor & 54.2 & 94.5 & 20.68 & 33.86 \\
\hline
\end{tabular}

Table 2: Result of temperature and heating value of aluminum sheet

\begin{tabular}{llllll}
\hline Testing condition & & Temperature $\left({ }^{\circ} \mathrm{C}\right)$ & & \\
& & - & & \\
& & Min & Max & Heating value $(\mathrm{kJ})$ & Ambient temperature $\left({ }^{\circ} \mathrm{C}\right)$ \\
\hline Horizontal & Un-drive motor & 54.6 & 84.7 & 5.02 & 33.39 \\
Horizontal & Un-drive motor & 74.1 & 97.2 & 4.17 & 36.94 \\
$16^{\circ}$ & Un-drive motor & 58.2 & 93.4 & 1.65 & 34.04 \\
$16^{\circ}$ & Drive motor & 56.2 & 89.4 & 4.38 & 33.86 \\
\hline
\end{tabular}

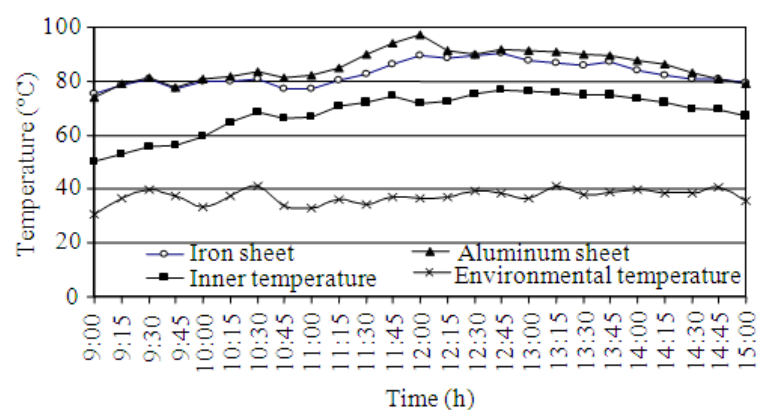

Fig. 3: Temperature of solar receivers in laying the unit horizontally

Figure 3 shows the inside of solar energy receiver, temperature of iron and aluminum sheet and ambient temperature. The temperature of iron and aluminum sheet tends to increase according to the temperature inside solar radiation receiver to the extent that it is at the highest level of 90.6 and $97.2{ }^{\circ} \mathrm{C}$ at $12.00-1.00 \mathrm{pm}$. whereas the ambient temperate is quite stable.

Temperature and heating of iron and aluminum sheet under various testing conditions: According to Table 1, the temperature and heating value of iron sheet put in place and moves upwards-downwards in vertical line, in laying the solar receiver horizontally and tilted at $16^{\circ}$ with plane level were $54.2-94.5^{\circ} \mathrm{C}$; the highest temperature of iron sheet was $94.5^{\circ} \mathrm{C}$ under the condition of driving motor so that iron sheet could move upwards-downwards in vertical line and put to be tilted at $16^{\circ}$ with plane level; this shows that laying the unit to be tilted and the moving of result of the highest level of difference of average temperature of iron sheet and ambient temperature under equation whereas the second highest temperature of iron sheet is $90.6^{\circ} \mathrm{C}$ under the condition that the iron sheet moves upwarddownwards in vertical line and lay the unit horizontally.
According to Table 2, the result of temperature and heating value of aluminum sheet when laying the unit horizontally and driving motor to move aluminum sheet upwards-downwards in vertical line in order to receive solar radiation from dual parabolic curve result to be $97.2^{\circ} \mathrm{C}$; secondly it is the laying of the unit to be tilted at 16 Degree with plane level and un-drive motor, this makes the temperature of aluminum to be $93.4^{\circ} \mathrm{C}$. It shows that driving motor or tilting solar radiation receiver at $16^{\circ}$ with plane level results in the perpendicular of light and the spread of sunlight from parabolic dual trough to cover all area while in the calculation of heating value of aluminum, it was found that the condition of laying the unit horizontally and undrive motor and tilting at $16^{\circ}$ with plane level and drive motor provides heating value of 5.02 and $4.38 \mathrm{~kJ}$, respectively; this may be because the ambient temperature of testing under such condition is lower to 33.39 and $33.86^{\circ} \mathrm{C}$ that makes the difference of temperature under Equation 1 become high under such testing condition and this increases the heating value of aluminum sheet.

\section{CONCLUSION}

According to the result of the experiment in laying the unit horizontally and driving motor leading to total temperature of the unit to be of the highest value, the highest temperature of iron sheet obtained was $90.6^{\circ} \mathrm{C}$, the highest temperature of aluminum was $97.2^{\circ} \mathrm{C}$; secondly it was the condition of laying the unit to be tilted at $16^{\circ}$ with plane level and drive motor. The highest temperature of iron obtained was $94.5^{\circ} \mathrm{C}$ and the highest temperature of aluminum was $89.4^{\circ} \mathrm{C}$; this reveals that the driving of motor and the tilting solar radiation receiver at $16^{\circ}$ with plane level leads to the fact that the perpendicular of light and the spread of sunlight from parabolic dual trough cover all area. 


\section{ACKNOWLEDGEMENT}

The researcher would like to express their sincere thanks to the Bio-Energy Research Laboratory, Faculty of Engineering, Mahasarakham University for the financial support, Assoc. Prof. Dr. Singthong Patanasethanon for wholehearted assistance and valuable advice in this experiment.

\section{REFERENCES}

Craxford, S.R., 1983. Pollution from lead in petrol. Oil Petrochem. Pollut., 1: 285-290.

Energy Research Institute, 2009. Information System on Energy and Environment of Thailand [online]. Chulalongkorn University.

http://www.teenet.chula.ac.th/usefull/detail5.asp?I $\mathrm{D}=176$
Gao, X. and S. Chen, 2008. Petroleum pollution in surface sediments of Daya Bay, South China, revealed by chemical fingerprinting of aliphatic and alicyclic hydrocarbons. Estuarine Coast. Shelf Sci., 80: 95-102.

Ministry of Energy, 2008. Renewable energy form. http://www.energy.go.th/moen/Index.aspx?MenuI $\mathrm{D}=71$ 